\title{
Gary Victor, Clair de mambo
}

\section{Monica Blondi}

\section{(2) OpenEdition}

\section{Journals}

\section{Edizione digitale}

URL: http://journals.openedition.org/studifrancesi/8115

DOI: 10.4000/studifrancesi.8115

ISSN: 2427-5856

\section{Editore}

Rosenberg \& Sellier

\section{Edizione cartacea}

Data di pubblicazione: 1 juillet 2009

Paginazione: 454-455

ISSN: 0039-2944

\section{Notizia bibliografica digitale}

Monica Blondi, «Gary Victor, Clair de mambo», Studi Francesi [Online], 158 (LIII | II) | 2009, online dal 30 novembre 2015, consultato il 08 janvier 2021. URL: http://journals.openedition.org/studifrancesi/8115 ; DOI: https://doi.org/10.4000/studifrancesi.8115

\section{Questo documento è stato generato automaticamente il 8 janvier 2021.}

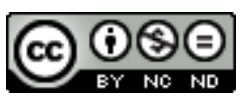

Studi Francesi è distribuita con Licenza Creative Commons Attribuzione - Non commerciale - Non opere derivate 4.0 Internazionale. 


\title{
Gary Victor, Clair de mambo
}

\author{
Monica Blondi
}

\section{NOTIZIA}

GARY VICTOR, Clair de mambo, La Roque d'Anthéron, Vents d'Ailleurs, 2007, pp. 216.

1 Al centro di questo primo romanzo di Gary Victor, pubblicato per la prima volta a Portau-Prince nel 1990, c'è il rapporto profondo che lega potere politico e vudù nella società haitiana fin dagli albori. Non è un caso che proprio una cerimonia vudù, tenutasi al Bois-Caïman nel 1791, sia universalmente considerata come il punto di partenza della rivolta che portò il paese all'indipendenza. Qui in particolare, attraverso la parabola di ascesa e caduta del candidato al soglio presidenziale Hannibal Sérafin, si evidenzia il lato demoniaco del potere, nonché le contraddizioni che sembrano caratterizzare ogni leader politico haitiano. Sérafin è figlio di un notaio che si è arricchito ingiustamente durante l'occupazione americana espropriando i contadini delle loro terre e poi denunciando e facendo imprigionare centinaia di persone per appropriarsi dei loro beni sotto il regime di Duvalier. Dopo gli studi, compiuti nelle migliori scuole come competeva ad ogni rampollo di élite, aveva viaggiato per il mondo e, dopo la morte del padre, si era stabilito a New York in veste di esiliato politico. Qui era divenuto membro di spicco della lotta antiduvalierista, organizzando marce davanti all'ambasciata haitiana e diffondendo appassionati messaggi patriottici dai microfoni di una radio. La sua incursione nel palazzo delle Nazioni Unite, dove si trovava in visita Jean-Claude Duvalier, aveva fatto di lui l'oppositore più popolare. Avvolto nella bandiera haitiana, aveva strappato il microfono al giovane presidente e tenuto un commovente discorso sulla reale situazione del suo paese, ostaggio della miseria e della corruzione dei suoi leader politici. Era diventato così il punto di riferimento per i suoi compatrioti in esilio, tenendo conferenze nelle università americane e organizzando ovunque cortei di protesta. Fino alla decisione di tornare ad Haiti, spinto dal desiderio di aiutare concretamente il suo paese. 
2 A Grand-Goâve, dove si stabilisce con la sua affascinante moglie bianca, può contare sulla stima del serafico Lanjélus, il vecchio pescatore, ex-combattente ai tempi dell'occupazione americana, fiducioso che Sérafin, a differenza dei suoi predecessori, avrebbe governato onestamente senza anteporre l'interesse personale al bene del paese. Al fine di garantirne l'elezione, Lanjélus decide di assicurargli la protezione di Agwe, il dio del mare, al quale era devoto. Anni prima, infatti, Agwe lo aveva salvato da una violenta tempesta mentre si trovava al largo con la sua barca. Sérafin accetta l'offerta del vecchio pescatore, memore delle parole del padre sullo stretto legame, ad Haiti, tra potere e vudù, acconsentendo a sottoporsi a un rito officiato in alto mare da Madan Sorel, la sensuale sacerdotessa mambo, che lo avrebbe "presentato" ad Agwe. In cambio, Sérafin avrebbe dovuto offrire al dio del mare la sua bellissima moglie. Entra così in scena il giovane Sonson Pipirit, personaggio che rappresenta lo stereotipo del dongiovanni caraibico: egli infatti vive stabilmente con una concubina ma è anche l'amante di Madan Sorel. In più si è anche invaghito della bella moglie di Sérafin ed è deciso a sedurla in tutti modi. Riesce nel suo intento con l'inganno proprio grazie a Madan Sorel, la quale gli consente di partecipare al rito facendolo passare per l'incarnazione di Agwe. Sotto lo sguardo estatico di Sérafin, Sonson non ha alcuna difficoltà a possederne la moglie.

Dopo il rito, Sérafin diventa ministro e fonda uno schieramento politico insieme ai suoi accoliti. Nonostante le buone intenzioni iniziali, ben presto anch'egli si rivela uguale ai suoi predecessori: un aspirante leader affetto dal culto della personalità, avido di potere e ricchezza. Al fine di affrettare i tempi della sua elezione, lo vediamo accettare la proposta del malvagio e deforme Djo Kokobe, il capo della setta satanica dei Dezose, che gli aveva assicurato potere assoluto in cambio di un posto come capo della polizia rurale. Djo Kokobe viene descritto come una variante infernale del gobbo di NotreDame. Inviso dalla folla per il suo aspetto ripugnante e per la crudeltà, veniva contattato segretamente da presidenti, ministri, generali e commercianti che confidavano nei suoi poteri per arricchirsi, ottenere il potere, conquistare la donna amata o danneggiare un rivale. È lui stesso ad ammettere che: «l'Histoire de ce pays, c'est la victoire perpétuelle du Mal sur le Bien». Suo padre, il terrificante Vlen, era stato a sua volta capo di una società segreta che praticava la magia nera. Pare che perfino François Duvalier si fosse rivolto a lui prima delle elezioni presidenziali del 1957, da cui era uscito vincitore. La notizia del patto stretto da Hannibal Sérafin con il demoniaco Djo Kokobe getta nello sconforto sia Lanjélus che Madan Sorel, consapevoli delle conseguenze funeste di questa infernale alleanza. Deluso dal candidato da lui sostenuto con tanto entusiasmo, il vecchio pescatore, che aveva combattuto valorosamente al fianco di Charlemagne Péralte durante la rivoluzione dei cacos, i contadini che si ribellarono all'invasione dei marines, imbraccia per un'ultima volta il suo fucile e uccide Hannibal Sérafin, prima di venire a sua volta ucciso da una guardia. Lo scontro finale tra magia bianca e magia nera che vede opporsi Madan Sorel a Djo Kokobe, decreta la sconfitta e la distruzione di quest'ultimo. Nella sempiterna lotta tra il Bene e il Male, smentendo un'antica maledizione, per una volta sembra trionfare il primo. 